\title{
ANALISIS PELAYANAN TRANSPORTASI BUS PERSPEKTIF ETIKA BISNIS ISLAM (STUDI KASUS PERUSAHAAN OTOBUS PT MINTO LESTARI JAYA GAMBIRAN BANYUWANGI)
}

\author{
Nur Roikhatul Jannah \\ Institut Agama Islam Negeri Ponorogo \\ Email: roikhatul367@gmail.com
}

\begin{abstract}
The purpose of this study is to analyze the transportation service of buses islamic business ethics perspective. Research will be about the theory of good service according to islamic business ethics. This type of research uses qualitative descriptive. With informal snowball collection techniques. On researcher obtained from interviews to bus business owners, bus drivers, and bus passengers in PT company. Minto Lestari Jaya which is located in the village of Jajag Gambiran, Banyuwangi. The results by the researchers showed that the services provided by bus drivers were effective. The officer has been polite and serves well in accordance with the teachings of the Prophet Muhammad SAW taught in the book Of Islamic Business Ethics by Fakhry Zamzam and Havis Aravik. The principles of Islamic business ethics include the following principles of business ethics: the first principle of autonomy, the second the honesty, the third the Principle of justice, the fourth principle of mutual benefit, the five Principles of integrity.
\end{abstract}

Keywords: Service, Islamic Business Ethics, Transportation, Bus

Abstrak : Tujuan penelitian ini adalah untuk menganalisis pelayanan transportasi bus perspektif etika bisnis islam. Penelitian akan mendeskripsikan tentang teori pelayanan yang baik menurut etika bisnis islam. Jenis penelitian ini menggunakan deskriptif kualitatif. Dengan teknik pengumpulan informal snowball. Pada peneliti diperoleh dari wawancara kepada pemilik usaha Otobus, pengemudi bus, dan penumpang bus di perusahaan PT Minto Lestari Jaya yang beralamat di Desa Jajag Gambiran, Banyuwangi. Hasil yang dilakukan oleh peneliti menunjukkan bahwa pelayanan yan diberikan oleh pengemudi bus sudah efektif. Petugas sudah sopan dan melayani dengan baik sesuai dengan ajaran Nabi Muhammad SAW yang diajarkan alam buku Etika Bisnis Islam karya Fakhry Zamzam dan Havis Aravik. Prinsip-prinsip etika bisnis islam meliputi Prinsip-prinsip etika bisnis sebagai berikut: yang pertama Prinsip otonomi, kedua kejujuran, ketiga Prinsip keadilan, keempat Prinsip saling menguntungkan, kelima Prinsip integritas moral.

Kata Kunci: Etika Bisnis Islam, Trasporasi, Otobus, Jasa

\section{PENDAHULUAN}

Pelayanan merupakan hal yang perlu dalam menjalankan kegiatan manusia sehari-hari, karena, pelayanan yang baik menunjukkan etika yang baik, seperti yang 
telah diajarkan oleh baginda Nabi Muhammad SAW antara lain: pertama kejujurannya, kejujuran adalah ucapan atau ungkapan yang sesungguhnya terjadi atau bisa disebut fakta. Kedua menyampaikan, menurut KBBI (Kamus Besar Bahsa Indonesia) arti menyampaikan adalah memberikan, memenuhi kewajiban, mengantarkan berarti setiap ada laporan tentang hasil usaha transportasi sampaikan kepada perusahaan yang sesungguhnya sampaikan hal-hal yang terjadi sekiranya itu penting bagi perusahaan. Ketiga kecerdasannya, arti kecerdasan menurut KKBI ialah kesempurnaan perkembangan akal budi seperti kepadaian, ketajaman pikiran. Dan yang keempat dapat dipercaya yang artinya perilaku apabila diberikan kepercayaan/perintah untuk dijalankan dengan baik sehinga memberikan rasa aman kepada pemberi kepercayaan, seperti perusahaan memberi kepercayaan kepada pengemudi untuk memberikan pelayanan baik kepada penumpang. Empat prinsip yang diajarkan oleh baginda Nabi Muhammad SAW telah mencontohkan kepada umatnya untuk menjalankan kehidupan dengan pelayanan penuh kepada orang lain, supaya orang lain tidak merasakan sakit hati dan kecewa.

Dalam pelayanan trasnsportasi ada tiga yaitu transportasi darat, transportasi laut dan transportasi udara. Transportasi merupakan pengangkutan barang oleh berbagai jenis kendaraaan sesuai dengan kemajuan teknologi. Satu Transportasi merupakan unsur yang sangat berpengaruh dalam roda perekonomian. Semua aspek kehidupan bangsa tergantung pada sektor transportasi, yang berfungsi sebagai pendorong pertumbuhan ekonomi. Setiap perusahaan memiliki fasilitas yang baik dan memadai untuk memuaskan penumpang, khususnya pada transportasi darat seperti transportasi bus PO (perusahaan otobus) PT Minto Lestari Jaya dalam penerapan kepuasan penumpang sudah efektif, tetapi alangkah baiknya pelayanannya menerapkan etika bisnis islam. Dalam etika bisnis Islam telah dijelaskan tentang teori pelayanan yang baik, dan prinsip-prinsip etika bisnis Islam.

PO (Perusahaan Otobus) PT Minto Lestari Jaya merupakan salah satu perusahaan bisnis yang bergerak di bidang jasa transportasi. Perusahaan ini dimiliki oleh Bapak Hermanto. Perusahaan ini terletak di Desa Jajag, Kecamatan Gambiran, Kabupaten Banyuwangi. Bus pada perusahaan ini melayani trayek antar kota provinsi, mulai jurusan Banyuwangi-Situbondo dan menyediakan bus pariwisata dengan fasilitas yang memadai. Untuk harganya menyesuaikan jarak jauh yang ditempuh dalam tujuan perjalanan penumpang. Penghasilan PO (perusahaan otobus) PT Minto Lestari Jaya 
tersebut akan dibagi menjadi 3 yaitu pertama, untuk perusahaan PT Minto Lestari Jaya. kedua, untuk pengemudi dan crew, ketiga, untuk beban kendaraan.

\section{TINJAUAN LITERATUR}

\section{Prinsip dalam Bisnis}

Menurut Shanti Kasistawati (2020), terdapat 4 prinsip dalam bisnis yaitu (Shanti Kasistawati, dkk, 2020)):

a. shidiq (jujur), jujur dalam melakukan transaksi dan memberikan informasi kepada konsumen.

b. amanah (dapat dipercaya) berarti bertanggung jawab atas semua yang dilakukan seperti: bertanggung jawab kepada konsumen atas kepercayaannya dalam suatu pekerjaan, bertanggung jawab kepada konsumen jika terjadi kecelakaan yang tidak terduga/ tidak disengaja.

c. fathonah (profesional) disini dapat diartikan semua pekerjaan terutama kepada gojek berusaha bekerja dengan maksimal dalam melakukan suatu pekerjaan, karena jika hasil yang baik maka otomatis konsumen akan merasakan senang dan puas atas pekejaan yang dilakukannya.

d. tablig (kesopanan dan keramahan), kesopanan dan keramahan termasuk inti atau sesuatu yang penting dari pelayanan, pelayanan baik pasti mengamalkan sikap kesopanan dan keramahan dalam melayani konsumen.

\section{Pelayanan}

Putri Ayu Anggraini (2018) mendefinisikan pelayanan sebagai suatu proses pemenuhan kebutuhan manusia secara langsung dan bersifat tidak berwujud, karena pelayanan termasuk usaha jasa, pelayanan bisa juga dikatakan sebagai salah satu strategi dalam bisnis (Anggraini, 2018). Adapun karakteristik pelayanan yang baik antara lain: sifat pelayanan tidak bisa diraba hanya bisa dirasakan, pelayanan berlawanan dengan usaha barang jadi yang berwujud. jika Pelayanan sudah menghasilkan kepuasan kepada pelanggan, maka kualitas bisnis yang diharapkan oleh pelanggan, kualitas bisa diartikan sebagai memenuhi harapan pelanggan, kondisi mutu yang setiap saat mengalami perubahan lebih baik. Arif Wibowo (2014) menjelaskan, kualitas yang tinggi dihasilkan dari pelayanan yang baik dan sesuai dengan prinsip-prinsipnya (Wibowo, 2014). 
Pelayanan merupakan sifat untuk memuaskan pelanggan yang tidak terwujud dan cepat hilang.

\section{Etika Bisnis Islam}

Etika bisnis islam adalah akhlak yang menjelaskan tentang bisnis sesuai dengan prinsip-prinsip ajaran islam (Juliyani, 2016). Akhlak mempunyai kedudukan yang sangat penting bagi kehidupan manusia, baik sebagai individu, maupun kelompok. Akhlak yang baik akan memberikan rasa cinta kepada orang lain. Etika bisnis dalam islam menerapkan kesatuan, kepercayaan, keseimbangan, keadilan, bertanggung jawab, dan melakukan hal-hal baik dalam hidup.

Jadi dapat disimpulkan bahwa pelayanan sangat penting dalam usaha barang atau jasa karena pelayanan yang baik bisa membawa image perusahaan selain itu pelanggan juga merasakan puas dan bisa mengulangi dilain waktu. Transportasi yang dicari pelanggan pada umumnya adalah yang simpel, mudah dicari, harga terjangkau, tidak menunggu lama, pelayanan cepat, dan pelayanan baik yang sesuai prinsip-prinsip etika bisnis islam yaitu: shidiq, tabliq, fathonah, amanah. Dan akhlak yang baik.

\section{METODE PENELITIAN}

Menurut Etta Mamang, dkk (2010:26) Penelitian kualitatif adalah penelitian yang datanya dinyatakan dalam bentuk verbal dan dianalisis tanpa teknik statistik. Penelitan kualitatif termasuk penelitian yang menggunakan data, sehingga tidak ada pengkoondisian pada objek.

Penelitian ini menggunakan jenis penelitian kualitatif dan menjelaskan penelitian melalui data hasil di lapangan dan wawancara untuk mendapatkan hasil yang lebih valid. Kajian pustaka juga digunakan untuk empertajam analisa deskriptif dengan penelitian yang diteliti, data yang diambil dengan cara langsung turun di lapangan, sehingga peneliti mengetahui informasi-informasi yang sesuai dan jelas. Subjek penrelitian ini adalah PO (Perusahaan Otobus) PT Minto Lestari Jaya merupakan salah satu perusahaan bisnis yang bergerak di bidang jasa transportasi. Perusahaan ini terletak di Desa Jajag, Kecamatan Gambiran, Kabupaten Banyuwangi.

Bus pada perusahaan ini melayani trayek antar kota provinsi, mulai jurusan Banyuwangi-Situbondo dan menyediakan bus pariwisata dengan fasilitas yang memadai. Untuk harganya menyesuaikan jarak jauh yang ditempuh dalam tujuan 
perjalanan penumpang. Penghasilan PO (perusahaan otobus) PT Minto Lestari Jaya tersebut akan dibagi menjadi 3 yaitu pertama, untuk perusahaan PT Minto Lestari Jaya. kedua, untuk pengemudi dan crew, ketiga, untuk beban kendaraan.Pola pelayanan yang diterapkan di PT.Minto Lestari Jaya Banyuwangi,berdasarkan hasil penelitian di lapangan dan silang data penyesuaian komparasi dengan hasil wawancara terdapat adanya kesesuaian.

Wawancara dilakukan pada para penumpang,pengemudi bus dan juga pemilik perusahaan. Tujuan utama dari penelitian kualitatif adalah untuk memahami kondisi dengan cara memberikan pemaparan berupa penggambaran yang jelas pada lapangan yang diteliti, sehingga menghasilkan sebuah teori (V. Wiratna Sujarweni, 2015:21-22). Alasan penelitian mengguanakan metode kualitatif adalah untuk mengetahui informasi secara rill atau nyata dalam lapangan tersebut. Penelitian dilakukan di PO (Perusahaan Otobus) PT Minto Lestari Jaya J1. Juanda, RT. 03 RW. 02, Desa Jajag, Kecamatan Gambiran, Kabupaten Banyuwangi.

Sumber data dalam penelitian adalah subjek dari mana data diperoleh. Apabila penelitian mengunakan kuesioner atau wawancara dalam pengumpulan datanya, maka sumber data tersebut responden, yaitu orang yang merespon atau menjawab pertanyaanpertanyaan peneliti, baik pertanyaan tertulis maupun lisan (Arikunto Suharsini, 2010:2). Teknik analisis data adalah metode dalam memproses data menjadi informasi. Saat melakukan suatu penelitian yang perlu dilakukan adalah menganalisis data, supaya data tersebut mudah dipahami.

Dengan demikian sumber data yang diperoleh dalam mencari informasi penelitian melalui wawancara dengan pengusaha atau pendiri Otobus PT Minto Lestari Jaya. Wawancara selanjutnya kepada pegawai atau crew perusahaan Otobus PT Minto Lestari Jaya, dan yang terakhir wawancara kepada penumpang atau konsumen, dengan strategi tersebut peneliti dapat mengetahui informasi fakta atau sesuai. Data adalah fakta, informasi yang digunakan sebagai pemecah masalah dalam penelitian. Data yang digunakan dalam penelitian ini adalah tentang pelayanan transportasi dalam penerapan etika bisnis Islam (Prastowo, 2016, 206).

Menurut Iryana Riski Kawasati, teknik pengumpulan data merupakan cara yang digunakan oleh peneliti untuk mengumpulkan data-data penelitian dari sumber data (subjek maupun sampel penelitian). Adapun pengecekan keabsahan data dalam penelitian, maka peneliti menggunakan metode triangulasi. KBBI (Kamus Besar Bahasa 
Indonesia) mengartikan Triangulasi adalah teknik navigasi yang menggunakan sifatsifat segitiga trigonometri. Triangulasi merupakan teknik untuk menguji kepercayaan data yang dilakukan dalam penelitian.Menjadi alasan kuat mengapa penelitian inipun menggunakan teknik triangulasi agar analisa deskriptif lebih kuat dan signifikan dengan hasil data dan hasil penelitian yang di lapangan.

Penelitian ini melakukan pengelolaan data berdasarkankan hasil dari lapangan maupun keputusan suatu penelitian. Pengelolaan data bertujuan untuk mempermudah dalam penelitian (Muh. Fitrah, dkk, 2017, hlm. 31). Setiap penelitian pasti ada hasil yang diteliti, hasil tersebut dari lapangan yang ditinjau. Dalam penelitian ini dapat dikembangkan kembali di subjek penelitian yang berbeda dan metode penelitian yang berbeda pula agar memiliki keragmanan hasil penelitian yang akan menambah khasanah khasanah keilmuan..

\section{HASIL DAN PEMBAHASAN}

\section{Pembahasan Kualitas Pelayanan Transportasi Bus}

Kualitas merupakan suatu faktor penting yang memberikan perusahaan untuk para konsumennya (Wibowo, 2014). Pelayanan merupakan suatu kinerja penampilan, tidak berwujud dan cepat hilang, lebih dapat dirasakan dari pada dimiliki, serta konsumen lebih dapat berpartisipasi aktif dalam proses mengkonsumsi jasa tersebut. Kualitas pelayanan adalah suatu instrumen dan strategi yang diberikan perusahaan untuk menarik minat konsumen untuk mengkonsumsi produk atau jasa yang diberikan, umumnya konsumen yang mengkonsumsi produk atau jasa, konsumen melihat dari kualitas yang diberikan serta pelayanannya, apabila kualitas pelayanan baik dan memuaskan konsumen akan merasakan kenyamanan dan berharap akan kembali dan mengulanginya lagi. Menurut KBBI (Kamus Besar Bahasa Indonesia) Pelayanan adalah usaha melayani kebutuhan orang lain dengan memperoleh imbalan (uang) jasa. Atau bisa dirtikan kebutuhan yang memperoleh imbal baik antara pengemudi atau penjual dan konsumen. M. Nur Rianto Al Arif (2010) mendefinisikan pelayanan sebagai sifat yang tidak bisa diraba hanya bisa dirasakan oleh jiwa pelanggan, pelayanan yang sangat berlawanan dengan barang jadi (Arif, 2010, hlm. 211). Adapun karakteristik pelayanan yang terbaik antara lain:

a. Pelayanan yang ada tindakan nyata seperti tindakan sosial. 
b. Produksi dan konsumsi dari pelayanan tidak dapat dipisahkan secara nyata, karena pada umumnya kejadian bersamaan dan terjadi ditempat yang sama.

Menurut Siti Fatimah (2019) pengertian transportasi adalah pegetahuan yang mempunyai hubungan dengan manajemen, pemasaran, ekonomi, undang-undang dan kebijakan pemerintah (Fatimah, 2019, hlm. 3). Transportasi berasal dari tambahnya sektor-sektor di suatu negara. Dari pemaparan definisi transportasi diatas dapat disimpulkan transportasi adalah suatu ilmu atau pengetahuan ekonomi yang bisa mengembangkan perekonomian di Indonesia dengan berbagai sektor-sektor. Transportasi pelayanan Perusahaan Otobus (PO) PT Minto Lestari Jaya perlu menerapkan teori-teori pelayanan. Tujuan teori pelayanan untuk memuaskan konsumen atau pelanggan yang mengkonsumsi transportasi darat otobus PT Minto Lestari Jaya. Berikut ini teori-teori pelayanan antara lain:

a. Transparan

Transparan merupakan pelayanan bersifat terbuka, mudah didapat dimanapun berada yang membutuhkan. PO (perusahaan otobus) PT Minto Lestari Jaya telah meberikan sarana dan prasarana dengan baik dan lengkap sehingga pelanggan merasakan puas atas layanan yng diberikan atas dasar teori transparan.

b. Akuntabilitas

Akuntabilitas merupakan pelayanan yang bisa dipertanggungjawabkan. Seperti didalam bus banyaknya pecopet atau pencurian yang sangat berbahaya bagi penumpang, jadi perusahaan otobus PT Minto Lestari Jaya atau transportasi darat lainnya untuk lebih memperhatikan akuntabilitas tersebut bertujuan untuk keamanan pada penumpang.

c. Kondisional

Kondisional merupakan kondisi dan kemamapuan memberi atau menerima pelayanan dengan prinsip etika islam. Bisa juga dengan prinsip lainnya.

d. Partisipatif

Partisipatif merupakan pelayanan yang dapat mendorong masyarakat dalam memperhatikan aspirasi, kebutuhan dan harapan pada penumpang transportasi darat. Perusahaan Otobus PT Minto Lestari jaya akan mendengarkan keluhankeluhan dari karyawan dan konsumen, seperti fasilitas makanan untuk supir bus, pelayanan lebih untuk konsumen. Hal tersebut perusahaan otobus PT Minto Lestari Jaya berusaha untuk memecahkan masalah dan risiko yang dihadapi, memfasilitasi 
makanan untuk supir dan pembelajaran melayani konsumen dengan prinsip etika bisnis islam. Hal tersebut bertujuan untuk kemajuan dalam berbisnis.

e. Kesamaan hak

Maksud dari kesamaan hak adalah pelayanan pada transportasi darat otobus dan transportasi lainnya tidak melakukan diskriminasi atau menggunakan cara perbedaan dari aspek suku, ras, agama, golongan, status sosial dan lain-lain.

f. Keseimbangan Hak dan Kewajiban

Pelayanan benar-benar mempertimbangkan aspek keadilan dalam melayani konsumen. Supaya terhindar dari kecemburuan sosial dan mempertahankan pelayanan yang berkualitas.

Dapat disimpulkan pengertian kualitas pelayanan transportasi adalah usaha melayani hubungan dengan penuh rasa kasih sayang sehingga konsumen merasakan puas dan merasakan dihormati pada transportasi darat. PO (perusahaan otobus) PT Minto Lestari Jaya dalam pelayanannya sudah efektif karena sarana dan prasarana sangat diperhatikan oleh PO (Perusahaan Otobus) PT Minto Lestari Jaya.

\section{Pelayanan Perspektif Etika Bisnis Islam}

Etika berasal dari bahasa Yunani yaitu ethos yang berarti jiwa atau roh yang mendasari tindakan (Samad, 2016, hlm. 7). Kemudian etika dikembangkan menjadi peraturan dalam manusia. Sedangkan menurut Buchari Alma, dkk (2016:378) moral dalam bahasa Indonesia dipahami sebagai susila, yaitu perilaku, tindakan yang sesuai dengan pandangan baik, baik dalam masyarakat, baik dalam sosial dan baik dalam lingkungan sekitar(Alma dkk, 2016, hlm. 378). Perbedaan moral dan etika yaitu jika etika lebih banyak kepada teori atau tindakan langsung, sedangkan moral lebih banyak bersifat praktis atau dilihat dengan pandangan umum sekitar yang baik.

Dalam jurnal yang ditulis oleh Erly Yuliani (2016) mengutip Al-Ghazali dibuku Ihya' Ulumuddin menjelaskan pengertian etika khuluq adalah suatu yang tetap dalam jiwa, tidak membutuhkan pikiran (Yuliani, 2016). Dengan demikian etika bisnis dapat disimpulkan dalam islam adalah akhlaq dalam menjalankan bisnis sesuai dengan nilainilai islam, prinsip-prinsip islam, sehingga dalam melaksanakan bisnis atau usahanya tidak perlu ada kekhawatiran lagi, sebab sudah meyakini bahwa sesuatu yang benar akan menghasilkan perbuatan baik. 
Mukhtar Samad (2016) etika islam disamakan dengan kata budi pekerti, akhlaq, sopan santun dan lain sebagainya (Samad, 2016). Nabi Muhammad SAW diutus oleh Allah SWT untuk menyempurnakan atau memperbaiki akhlaq manusia. Maka umat Islam sangat dianjurkan untuk berbuat sopan santun terhadap umat Islam lainnya terlebihnya yang lebih tua, karena dengan akhlaq yang baik maka, akan mencerminkan hati dan prilaku yang baik. Hal tersebut akan menjadikan pelayanan etika bisnis dalam islam. Jika pelayanan baik maka akan menimbulkan rasa nyaman, aman, dan kepercayaan terhadap konsumen atau penumpang bus. Ernawan (2011) menjelaskan tentang prinsip-prinsip etika bisnis antara lain (Ernawan, 2011):

a. Prinsip Otonomi

Otonomi adalah kemampuan manusia dalam mengambil keputusan dan bertindak apa yang disudah direncanakan sebelumnya dan diputuskan serta mampu bertanggung jawab atas apa yang diputuskan tersebut. Dalam usaha bisnis prinsip otonomi sadar sepenuhnya atas kewajiban-kewajiban dalam usahanya, seperti mampu meminimalisir risiko-risiko usaha, mampu membangun kepercayaan, melayani pelanggan dan karyawan dengan baik sesuai ajaran Nabi Muahammad SAW.

b. Prinsip Kejujuran

Kejujuran kunci utama dalam usaha atau suatu keberhasilan, karena kejujuran mampu menumbuhkan kepercayaan penuh kepada konsumen dan orang lain. PT Minto Lestari Jaya melakukan kejujuran dalam harga dan tujuan konsumen yang ingin dituju.

c. Prinsip Keadilan

Keadilan dapat diartikan sama, tidak berpihak, tidak merasa dirugikan atas kepentingannya. Salah satu teori mengenai keadilan yang dikemukakakan oleh Aristoteles sebagai berikut:

1) Keadilan legal, berhubungan dengan keadilan secara individu atau kelompok.

2) Keadilan komunikatif, memenej hubungan yang sama antara orang yang satu dengan orang lain

3) Keadilan distributif, keadilan yang diciptakan perusahaan atau suatu usaha dengan cara pendistribusian secara merata dan tidak berpihak oleh siapapun.

d. Prinsip Saling Menguntungkan 
Prinsip saling menguntungkan membuat semua pihak dalam perusahaan bermanfaat bagi diri sendiri maupun orang lain.

e. Prinsip Integritas Moral

Prinsip integritas moral merupakan sikap konsisten yang kuat, sehingga seseorang tersebut menghasilkan keyakinan, kepercayaan terhadap orang lain.

Dari kelima prinsip tersebut dapat disimpukan bahwa prinsip-prinsip etika bisnis sangatlah penting untuk pegembangan etika bisnis. Rasulullah SAW. juga mengajarkan pada umatnya untuk menerapkan prinsip-prinsip etika bisnis, yaitu sebagai berikut:

1) Shidiq (jujur)

2) Fathonah (cerdas)

3) Amanah (dapat dipercaya)

4) Tabligh (menyampaikan)

Dari prinsip-prinsip tersebut diterapkan dengan baik bagi Perusahaan Otobus (PO) PT Minto Lestari Jaya. Prinsip-prinsip etika bisnis islam jika diterapkan oleh perusahaan lainnya pastilah usaha bisnisnya berkembang dengan pesat dan penghasilan meningkat karena memprioritaskan kepuasan konsumen atau pelanggan.

\section{Hasil Observasi Pelayanan Perusahaan Otobus (PO) PT Minto Lestari Jaya}

Pelaksanaan peninjauan penelitian di Perusahaan Otobus (PO) PT Minto Lestari Jaya yang beralamatkan di RT. 03 RW. 02, Desa Jajag, Kecamatan Gambiran, Kabupaten Banyuwangi, penempatan perusahaan otobus (PO) tersebut sangat startegis karena daerah Desa Jajag terdapat terminal, jarak antara perusahaan otobus (PO) PT Minto Lestari Jaya dengan terminal sekitar $2 \mathrm{~km}$. Untuk pelayanan pun para supir armada bus PT Minto Lestari Jaya juga ramah dengan para penumpang yang hendak melakukan perjalanan antar kota di dalam kabupaten dan di luar kabupaten. Kami bertanya kepada salah satu penumpang yang bernama bapak Imam Rofi'I dari Dusun Gembolo, Desa Purwodadi, Kecamatan Gambiran, Kabupaten Banyuwangi yang akan melakukan perjalanan ke Banyuwangi kota.

Menurutnya, alasan beliau selalu menaiki bus PT Minto Lesrtari Jaya ke Banyuwangi kota untuk bekerja dikarenakan tarifnya yang masih terbilang murah bagi kalangan menengah kebawah serta supir dan kernet yang terbilang ramah yang sudah menerapkan prinsip-prinsip etika bisnis islam seperti prinsip kejujuran, prinsip 
tanggung jawab, prinsip keadilan, dll. Selain pelayanan tarif transportasi bus PT Minto Lestari Jaya juga melayani membawa tas penumpang sampai penumpang naik dan sebaliknya jika penumpang mau turun karena sudah sampai tujuan crew bus akan membantu membawakan barang-barang yang dibawa penumpang. Berikut rincian pelaksanaan penelitian pelayanan PT Minto Lestari Jaya

Tabel 1. Pelaksanaan Penelitian Pelayanan PT Minto Lestari Jaya

\begin{tabular}{lll}
\hline Kegiatan ke & Tanggal & Nama kegiatan \\
\hline 1. & 7 Maret 2021 & Izin kepada pemilik perusahaan PT Minto \\
& Lestari Jaya bapak Hermanto \\
\hline 2. & 8 Maret 2021 & Wawancara kepada pemilik perusahaan PT \\
& Minto Lestari Jaya dan beberapa pegawai bus \\
\hline 3 & 10 Maret 2021 & Evaluasi kegiatan penelitian \\
\hline
\end{tabular}
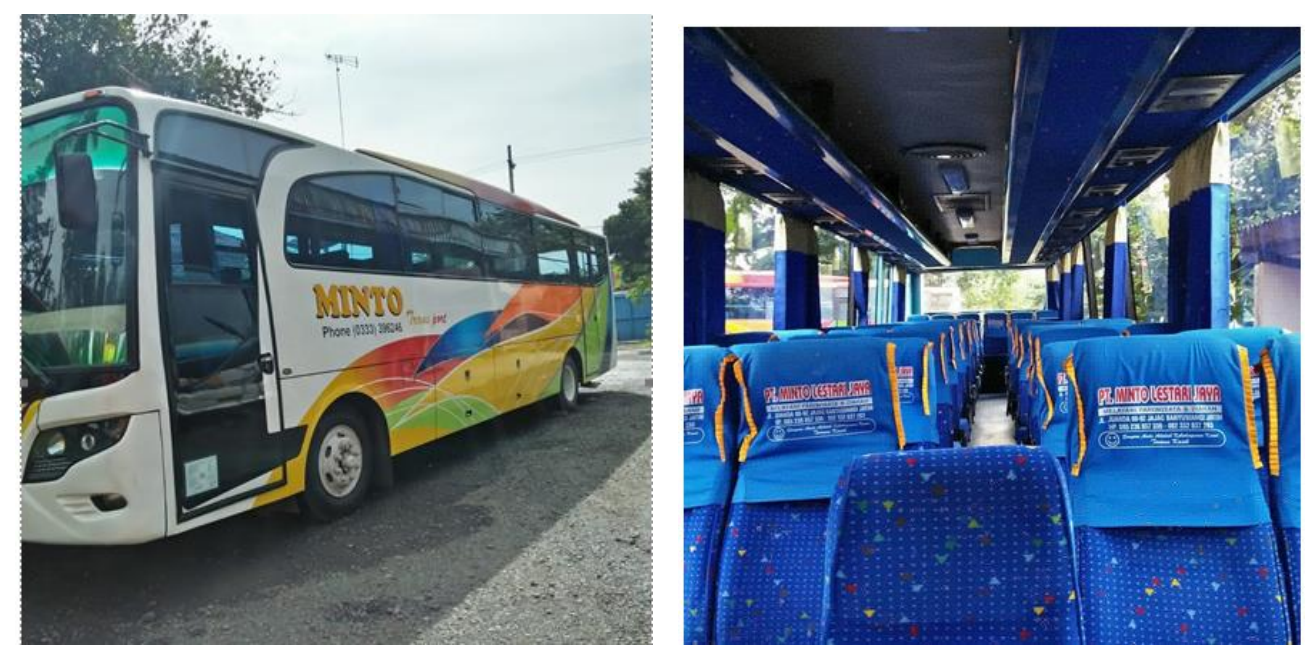

Gambar 1. Bus PT Minto Lestari Jaya tampak samping dan tampak dalam

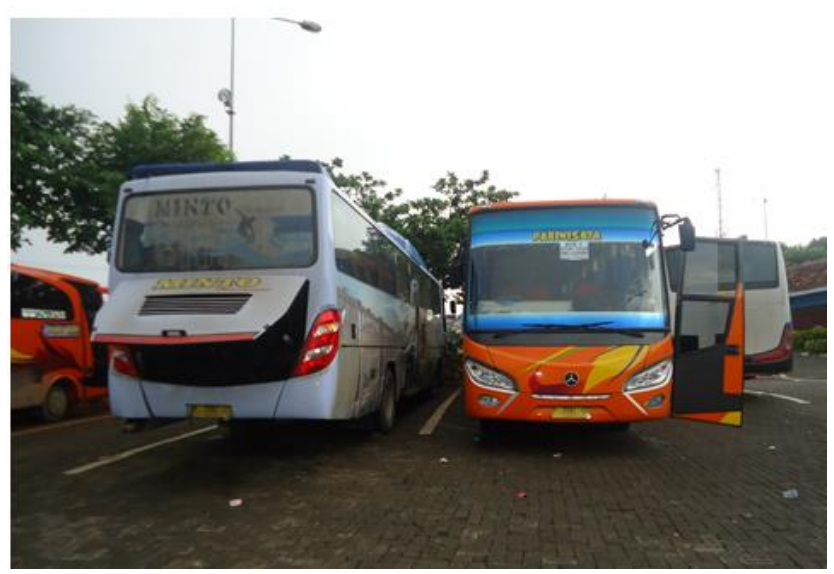

Gambar 2 : Dua unit Bus Minto yang terparkir di area Wisata Bahari Lamongan ( WBL ) 
Transportasi bus PT Minto Lestari Jaya juga melayani bus pariwisata. Pada tanggal 27 Desember 2019 armada bus PT Minto Lestari Jaya mengoperasikan dua unit bus pariwisata dengan tujuan Wisata Bahari Lamongan yang mana dua unit bus ini disewa oleh siswa SMPN 3 Glenmore, Banyuwangi. PT Minto Lestari Jaya memberikan pelayanan kepada konsumen dengan dilengkapi oleh sarana dan prasarana yang mendukung, bertujuan untuk memudahkan dalam pengoperasian pelayanan kepada konsumen. Adapun fasilitas yang dimiliki oleh PT Minto Lestari Jaya seperti tempat duduk yang nyaman, tisu, plastik, tempat sampah, garasi untuk meletakkan tas, AC, televisi, tempat charger HP, dll.

Pelayanan yang diberikan selama perjalanan bus pariwisata tujuan Lamongan WBL yakni memberikan kemudahan informasi untuk proses pemesanan paket wisata sesuai dengan kebutuhan konsumen, crew menggunakan seragam agar mudah dikenali oleh peserta tour, crew memakai wajib sepatu, crew dilengkapi dengan handy talky untuk memudahkan pengawasan, menggunakan bus pariwisata, bus stand by dilokasi penjemputan sebelum keberangkatan, pengawasan kelengkapan konsumen dengan teliti, pemberian informasi kepada tour tentang waktu, tujuan, dan prosedur tour yang baik, menyediakan air mineral setiap hari selama perjalanan, makan sesuai dengan program yang diinginkan konsumen, menyediakan banner utuk swafoto. Salain menyediakan layanan selama perjalanan perusahaan otobus (PO) PT Minto Lestar Jaya juga menyediakan layanan kesehatan dan asuransi seperti fasilitas P3K yang memadai dan fasilitas asuransi perjalanan wisata.

\section{KESIMPULAN}

Berdasarkan analisis pelayanan transportasi bus perspektif etika bisnis islam (studi kasus Perusahaan Otobus PT Minto Lestari Jaya Gabiran Banyuwangi), di Jl. Juanda, RT. 03 RW. 02 Dusun Petahunan, Desa Jajag, Kecamatan Gambiran, Kabupaten Banyuwangi yang telah dilaksanakan penelitian dapat ditarik kesimpulan sebagai berikut:

1. Pelayanan merupakan indikator utama dalam mendirikan bisnis, karena pelayanan yang baik dapat menarik konsumen untuk kembali dan dapat menambah konsumen lebih banyak, dan dapat meningkatkan penghasilan perusahaan otobus PT Minto Lestari Jaya juga meningkat. 
2. Konsumen dapat merasakan pelayanan yang memuaskan dengan penerapan prinsip dan teori pelayanan dengan perspektif etika bisnis islam sehingga perkembangan perusahaan otobus PT Minto Lestari Jaya meningkat.

3. Asas etika bisnis Islam dalam perusahaan otobus PT Minto Lestari Jaya telah diterapkan sesuai kaidah yang termaktub dalam Qur'an dan Sunnah Nabi sehingga menimbulkan kepuasan di bidang pelayanan dalam hal transportasi dalam pandangan konsumen.

\section{REFFRENSI}

Arif, M. N. R. A. (2010). Dasar-Dasar Pemasaran Bank Syariah. Bandung: Alfabeta. Alma, B., \& Priansa, D. U. (2016). Manajemen Bisnis Syariah. Bandung: Alfabeta.

Anggraini, P. A. (2018). Skripsi. Studi Komperatif Pelayananan Taksi Online Dan Taksi Konvensional Terhadap Kepuasan Pelanggan Dalam Perspektif Ekonom Islam (Studi Pada Taksi Puspa Jaya Di Bandar Lampung). Universitas Islam Negeri Raden Intan Lampung.

Erni, E. R. (2011). Etika Bisnis. Bandung: Alfabeta.

Fatimah, S. (2019). Pengantar Transportasi. Ponorogo: Myria Pubisher.

Fitrah, M., Luthfiyah, (2017). Metodologi Penelitian: Penelitian Kualitatif, Tindakan Kelas \& Studi Kasus. Sukabumi: CV. Jejak.

Karistawati, S., Nurhayati, R., \& Rohmat, S. (2020). Pelayanan Jasa Sopir Gojek Online Kepada Konsumen Pada Aplikasi Gojek Online Cabang Purwakarta Dalam Prespektif Ekonomi Syariah. Eksisbank. 4(1).

Kawasati, I. R. Teknik Pengumpulan Data Metode Kualitatif. Sekolah Tinggi Agama Islam Negeri: STAIN Serong.

Mamang, E., \& Sopiah. (2010). Metode Penelitian: Pendekatan Praktis dalam Penelitian. Yogyakarta: Andi Publisher.

Prastowo, A. (2016). Metode Penelitian Kualitatif Dalam Perspektif Rancangan Penelitian. Jogjakarta: A-Ruzz Media.

Samad, M. (2016). Etika Bisnis Syariah Berbisnis Sesuai dengan Moral Islam. Yokyakarta: Percetakan Sunrise.

Suharsini, A. (2010). Prosedur Penelitian Suatu Pendekatan Praktek. Jakarta: Rineka Cipta.

Sujarweni, V. W. (2015). Metodologi Penelitian Bisnis\&Ekonomi . Yogyakarta: Pustaka Baru Press.

Wibowo, A. (2014). Pengaruh Kualitas Pelayanan Transportasi Umumbus Trans Jogja Terhadap Kepuasan Konsumen . Jurnal Ilmu Manajemen. April 11(2)

Yuliani, E. (2016). Etika Bisnis Dalam Persepektif Islam. Jurnal Ummul Qura. Maret $7(1)$. 